\title{
Evaluating Academic Research Networks
}

\section{Damien Contandriopoulos, Catherine Larouche, and Arnaud Duhoux}

Université de Montréal

\begin{abstract}
Funding agencies and universities are increasingly searching for effective ways to support and strengthen a dynamic and competitive scientific research capacity. Many of their funding policies are based on the hypothesis that increased collaboration and networking between researchers and between institutions lead to improved scientific productivity. Although many studies have found positive correlations between academic collaborations and research performance, it is less clear how formal institutional networks contribute to this effect. Using social network analysis (SNA) methods, we highlight the distinction between what we define as "formal" institutional research networks and "organic" researcher networks. We also analyze the association between researchers' actual structural position in such networks and their scientific performance. The data used come from curriculum vitae information of 125 researchers in two provincially funded research networks in Quebec, Canada. Our findings confirm a positive correlation between collaborations and research productivity. We also demonstrate that collaborations within the formal networks in our study constitute a relatively small component of the underlying organic network of collaborations. These findings contribute to the literature on evaluating policies and programs that pertain to institutional research networks and should stimulate research on the capacity of such networks to foster research productivity.
\end{abstract}

Keywords: academic performance, research collaboration, research funding policies, scientific productivity, social network analysis, university research centres

Résumé : Les universités et les agences de financement cherchent de plus en plus à renforcer de façon efficace une capacité de recherche scientifique dynamique et concurrentielle. Bon nombre de leurs politiques de financement sont fondées sur l'hypothèse qu'une amélioration de la collaboration et du réseautage entre les chercheurs et entre les établissements mène à une productivité scientifique accrue. De nombreuses études ont noté une corrélation positive entre les collaborations de recherche et le rendement en recherche, mais la contribution des réseaux institutionnels officiels à ce résultat reste nébuleuse. À l'aide de méthodes d'analyse des réseaux sociaux, nous mettons l'accent sur la distinction entre ce que nous définissons comme les réseaux institutionnels de recherche "officiels " et les réseaux "organiques " de chercheurs. Nous analysons aussi l'association entre les positions structurelles réelles

Corresponding author: Damien Contandriopoulos, School of Nursing, University of Victoria PO Box 1700 STN CSC, Victoria BC V8W 2Y2; damien1@uvic.ca. 
des chercheurs au sein de ces réseaux et leur rendement scientifique. Les données utilisées proviennent des curriculum vitae de 125 chercheurs membres de deux réseaux de recherche financés par la province du Québec (Canada). Nos résultats confirment une corrélation positive entre la collaboration et la productivité en recherche. Nous avons démontré que les collaborations au sein des réseaux officiels inclus dans notre étude ne constituent qu'une composante relativement modeste d'un réseau sous-jacent et organique de collaboration. Ces résultats contribuent au corpus sur l'évaluation de politiques et de programmes liés aux réseaux de recherche institutionnels et devraient stimuler la recherche sur la capacité qu'ont ces types de réseaux d’encourager la productivité en recherche.

Mots clés : rendement en recherche, collaboration en recherche, politiques de financement de la recherche, productivité scientifique, analyse des réseaux sociaux, centres de recherche universitaires

A dynamic and competitive scientific research capacity is seen as an important asset for the development, well-being, and wealth of nations and communities. Public funding agencies and universities are increasingly searching for effective ways to support and strengthen this capacity. Funding programs that support or incentivize collaboration and networking between researchers are one of the core strategies used to achieve this goal and are increasingly put forward in Canada and abroad (Canadian Institutes of Health Research [CIHR], 2015; Corley, Boardman, \& Bozeman, 2006; Defazio, Lockett, \& Wright, 2009; Fonds de recherche du Québec [FRQ-S], 2015).

Such programs rest on the underlying hypothesis that increased collaboration and networking between researchers lead to improved scientific productivity and outcomes (Kyvik, 2013; Ponomariov \& Boardman, 2010). Many studies have indeed found positive correlations between academic collaborations and research performance (Abbasi, Wigand, \& Hossain, 2014; Barjak \& Robinson, 2008; Dundar \& Lewis, 1998; Ebadi \& Schiffauerova, 2015a; Landry, Traore, \& Godin, 1996; Martín-Sempere, Garzón-García, \& Rey-Rocha, 2008). However, few studies analyze performance considering both formal institutional network collaborations and actual organic collaborations between researchers.

In the context of the management of two independent research networks, we developed a method for the monitoring and evaluation of a network's performance to deal with some of the issues related to the conceptualization and measurement of collaboration. Our hypothesis was that performance might be related to collaborations but that the collaborations that do have an impact on performance might not be limited to those developed in the context of the formal institutional networks that funding agencies create in this aim. The present paper showcases this evaluation method and concludes by discussing the potential implications of our findings for public funding policies pertaining to institutional research networks and for the evaluation of formal research networks' capacity to foster research productivity. 


\section{DEFINING COLLABORATION NETWORKS}

In this study, we distinguish between two types of networks: "formal" institutional research networks and underlying "organic" academic collaboration networks. Institutional research networks refer to the formal organizations, funded through public or private sources for a set period to advance specific goals, such as strengthening research capacity or increasing multidisciplinary, multi-sectoral, and international partnerships. Institutional networks usually comprise registered members and are bounded by administrative regulations. "Organic" underlying collaboration networks, on the other hand, represent the actual ties between researchers, created both through informal exchanges and formal collaborations in research activities. These underlying networks, the object of considerable attention in social sciences research (Lamont \& Molnár, 2002), have variously been described as invisible colleges (Crane, 1972), scientific communities or fields (Hagstrom, 1965), schools of thought, or social circles (Milard, 2014). They often predate the formation of institutional network structures and have boundaries that extend far beyond those of institutional networks. Such "organic" networks are shaped by, among other things, disciplinary field structuring (Bourdieu \& Passeron, 1970), methodological approaches (e.g., researchers using quantitative methods tend to seek more collaborators; Moody, 2004), institutional affiliations, funding opportunities, and individual preferences. For example, a researcher's collaboration network might include international collaborators who, even without regular in-person interactions, are much more significant than department colleagues or formal research network co-members (Hoekman, Frenken, \& Tijssen, 2010). Other individual motives for seeking and establishing collaborative connections include personal affinity, mentorship of early-career graduate students and researchers, and desire to advance a career (Lee \& Bozeman, 2005; Pezzoni, Sterzi, \& Lissoni, 2012). Given the many motives and factors at play, these informal collaboration networks constitute complex self-organizing structures in constant mutation (Leydesdorff \& Wagner, 2008). The conceptualization and impact of organic collaboration networks are discussed at length elsewhere (Contandriopoulos, Duhoux, Larouche, \& Perroux, 2016).

As stated earlier, a major trend in recent literature has been to look at how collaborative practices within scientific networks affect productivity (Abbasi et al., 2014; Abramo, D’Angelo, \& Di Costa, 2009; Barjak \& Robinson, 2008; Dundar \& Lewis, 1998; Landry et al., 1996; Lee \& Bozeman, 2005; MartínSempere et al., 2008). Positive correlations between research collaborations and performance are attributed mostly to the possibility of exchanging resources, knowledge, and experience (Ynalvez \& Shrum, 2011). Collaboration with peers provides both an informational advantage (timely and accurate access to valuable information) and a control advantage (strategic positioning in relation to partners' and competitors' actions) (Burt, 1992). Those social processes are also related to the broader concept of social capital and the benefits of being embedded in larger social communities (Bourdieu, 1980, 1984; Burt, 1992; Granovetter, 1983, 1985; Putnam, 2000). 
Structural network analysis (SNA) is a particularly useful tool for studying such links between scientific collaboration and productivity. SNA is a transdisciplinary approach focused on understanding the structure of relations connecting different elements. It has commonly been used to study the formation of informal communities or subgroups within institutional settings (Knoke \& Yang, 2008; Prell, 2012; Scott, 2000; Scott \& Carrington, 2011).

Within the field of SNA, Granovetter's $(1983,1985)$ theory on the strength of weak ties and Burt's (1992) arguments on "structural holes" help us understand the links between structural position and performance in heterogeneous network structures. According to these authors, weak tie connections (Granovetter, 1983), or being positioned in such a way as to bridge a "structural hole" within a network (Burt, 1992) can convey greater structural advantage than the number of collaborations an individual has. Granovetter (1983) developed his theory in relation to the labour market, demonstrating that a significant number of job-seekers were more likely to find a position through weak interpersonal connections than through close but redundant relationships. Burt uses the example of employees in a firm and suggests that non-redundant ties-those found in a network that has structural holes instead of being completely interconnected-are useful because employees are more likely to acquire new information and ideas through several less connected networks than if they remain in the same circle of interconnected people (Borgatti \& Halgin, 2011). Similarly, researchers likely derive limited benefit from developing new but redundant ties with close colleagues with whom they regularly collaborate. Even a non-redundant new tie to a colleague who belongs to an existing cluster of people with whom one regularly collaborates will probably have a limited impact on accessing new information and opportunities. On the other hand, developing a new collaboration with a researcher belonging to a group of people with whom no or few ties currently exist is likely to provide new insights, ideas, projects, and opportunities. Granovetter's and Burt's arguments are not entirely convergent and have been discussed at length elsewhere (Borgatti \& Halgin, 2011; Kilduff \& Brass, 2010), but both convincingly show that, at the structural level, competitive advantage stems not from strong and redundant links within the same groups but rather from inter-group weak ties, and that it is those who are in such bridging positions who benefit the most. The betweenness centrality (BC) metric described in the methods section, which we use as a measure of how central a given researcher is within his or her collaboration network, is conceptually related to the concepts of weak ties and structural holes.

Although many studies using SNA methods have looked at the relations between informal collaborative networks and scientific performance (Abbasi et al., 2014; Tuire \& Erno, 2001), and some at the relation between institutional research networks and scientific performance (Defazio et al., 2009), few have brought these three elements together. Ponomariov and Boardman's (2010) longitudinal study of the publication records of researchers before and during their affiliation with a specific research centre explored elements similar to those presented in this study. The authors showed that affiliation to a research centre did enhance publication 
productivity, mostly for junior faculty. Defazio et al's study on European Unionfunded research networks indicated that funding provided to those networks did enhance collaboration but that such collaboration did not necessarily lead to more productivity, at least in the short term. The authors concluded that it may be a combination of various knowledge and relationship strengths that results in productive collaborations. On a related note, Porac et al's (2004) study showed that an interdisciplinary institutional alliance between two existing research teams had a positive influence on productivity but that other factors particular to each team also influenced outcomes. Among these were the fact that individual team members maintained their own collaboration patterns and that "loose" rather than "tight" collaborative work practices were developed within the larger structure, allowing for "more diverse combinations of human capital" and greater scientific contributions (p. 676). Reaching a different conclusion, Ynalvez and Shrum (2011, p. 213) showed that, in resource-constrained research institutions, informal professional network ties had a greater impact on publication productivity than did affiliation with formal collaborative research groups. While tending to support the hypothesis that forming institutional networks has a positive influence on productivity, the literature also raises important nuances. On the more specific question of the strength-of-weak-ties theory, both Ebadi and Schiffauerova's (2015b) and Abbasi et al's (2014) studies suggested that there is a positive relation between a researcher's bridging position in a network and his or her scientific performance. Ebadi and Schiffauerova concluded that, to secure the research funding necessary to increase scientific productivity, it is better to multiply and diversify relations rather than to maintain close ties with only a few prominent researchers.

Overall, the literature clearly demonstrates that a researcher's structural position in the actual "organic" network of peer collaboration significantly influences his or her productivity (Contandriopoulos et al., 2016). However, there is much more ambiguity around whether formal "institutional" networks have a significant influence on the underlying organic structure. In plain language, it is unclear whether strategic funding programs aimed to enhance collaboration have an impact on productivity. In the next section, we showcase the method we developed to evaluate the impact of two institutional research networks in Quebec on researchers' collaborative patterns and performance.

\section{DATA COLLECTION AND ANALYSIS METHODS}

The data used in this study come from two Canadian provincial research networks. Both networks-identified here as X network and Y network-are healthrelated interdisciplinary networks funded by the FRQ-S, Quebec's government health-research funding agency. The $\mathrm{X}$ network also receives funding from university partners and the Ministry of Health and Social Services. At the time of the study, the FRQS was funding 18 such provincial networks, with the objective of strengthening research in each network's field and enhancing researchers' national and international competitiveness. The two networks pursue these objectives 
by supporting inter-individual and inter-university collaboration as well as by improving the impact and visibility of their members' research findings. They also provide seed money for regular members' applications to external funding competitions as well as financial support for students. Researchers must hold an academic faculty position to become regular members of these institutional health networks. The X network, funded in its present form since 2012, has members from eight different universities and was composed of 91 regular members at the time of data collection. The Y network, funded since 2002, is a larger network divided into strategic groupings. Our study focused on a single grouping composed of 62 regular members at the time of data collection. The overlap in formal membership between these two institutional networks was minimal; only three researchers were officially members of both networks.

\section{Compiling $X$ network and $Y$ network members' collaborative ties}

We chose to start our evaluation of the networks by mapping the actual ongoing collaborations of their members, whether established within or outside the two networks. This enabled us to analyze the underlying organic collaboration network in which X network and Y network members are embedded. We identified ongoing collaborations using each $\mathrm{X}$ network and Y network member's latest available CV (from 2014). We collected 83 X network CVs (91\% of all $91 \mathrm{X}$ network members' CVs) and 46 Y network CVs (74\% of all 62 Y network members' CVs).

Using CVs was favoured over using only co-authored publications to identify members' collaborators. Because of their accessibility, co-authored publications are one of the most common sources used to estimate a researcher's number of collaborators (Abbasi et al., 2014; Barjak \& Robinson, 2008; Ebadi \& Schiffauerova, 2015a; Katz \& Martin, 1997; Lakitan, Hidayat, \& Herlinda, 2012; Leydesdorff \& Wagner, 2008; Newman, 2004). However, co-authored papers are the manifestation of just one specific form of collaboration and do not account for other forms that may not necessarily result in co-authored papers (Duque et al., 2005; Ebadi \& Schiffauerova, 2015a). Co-authoring practices are also more common in some disciplines than in others; for example, Moody (2004) showed that, in sociology, researchers using quantitative methods publish significantly more co-authored papers than do qualitative researchers. Therefore, focusing on co-authorship alone to identify a researcher's collaborators might not be the most suitable method for examining interdisciplinary research structures, so we decided to broaden our focus and sample a wider scope of academic collaborations. As we aimed to sample inter-researcher collaborations as widely as possible, we included not only co-authors but also collaborators recorded in the CVs for ongoing grants and co-presented communications, as well as master's, doctoral, and postdoctoral students currently supervised or co-supervised. We considered as collaborators the co-authors named in published and accepted papers in peer-reviewed journals, book chapters, and research reports. Given the variability of authorship practices, we considered all eligible publications regardless of authorship position. We also 
assigned a temporal length of collaboration to each type of research activity considered, to develop a reliable representation of each X network and Y network member's network of collaborators at the time of their latest CV. The choice of length of time to attribute to previous collaborations was subjective. We used one year before the current date for a communication, two years before publication for an article, book, chapter, or report, four years for a master's student supervision, and six years for a doctoral student supervision.

In practical terms, we first collected the names of all researchers appearing in each X network and Y network member's CV to compile lists of collaborators for each of the $83 \mathrm{X}$ network and $46 \mathrm{Y}$ network members. Each list included collaborators who were regular $\mathrm{X}$ and $\mathrm{Y}$ network members, but also many others who were not formal members of these two networks and whom we called external collaborators. The lists compiled for each of the members represent their individual (ego-centred) collaboration networks. Using this data collection method, we elicited the names of 4,264 researchers in total (126 X network or Y network regular members and 4,138 external collaborators).

\section{Visualizing and analyzing underlying collaboration networks}

The X network's and Y network's underlying collaborative structures were mapped and analyzed using two steps: (1) gathering all the ego-centred networks into larger interconnected collaboration networks; and (2) computing the structural metrics for each researcher's position in these networks. First, the collaborators listed for X network members were aggregated into a unified network data set by transposing all the data collected into a single-mode matrix (collaborator $\mathrm{x}$ collaborator). The same process was repeated to create a network matrix for $\mathrm{Y}$ network members. A final matrix was created by merging both data sets.

While the extent of the network data set obtained is limited to $\mathrm{X}$ network and Y network members' direct external collaborators, these kinds of collaboration networks can expand outward exponentially. Although multi-step sampling can be used to map unbounded networks (Lewis, 2006), single-step sampling was more suited to this study since our focus was specifically on X and Y network members' positions within the larger network. The choice of sample size and boundaries remains a theoretical and methodological decision based on what appears most relevant to the context studied (Knoke \& Yang, 2008; Scott, 2000; Wasserman \& Faust, 1994). Our sample thus represented an X network- and Y network-centric network composed of all registered $\mathrm{X}$ network and $\mathrm{Y}$ network members and all their direct external collaborators.

The network matrices were imported into the open-source SNA software Cytoscape 3.2.1 to create visual representations (sociograms) of the aggregated underlying collaboration network data sets. Three different sociograms were produced: Figure 1 shows the underlying collaboration network of X network members; Figure 2 shows the underlying collaboration network of $\mathrm{Y}$ network members, and Figure 3 shows a single merged network including X network members, Y network members, and their collaborators. 


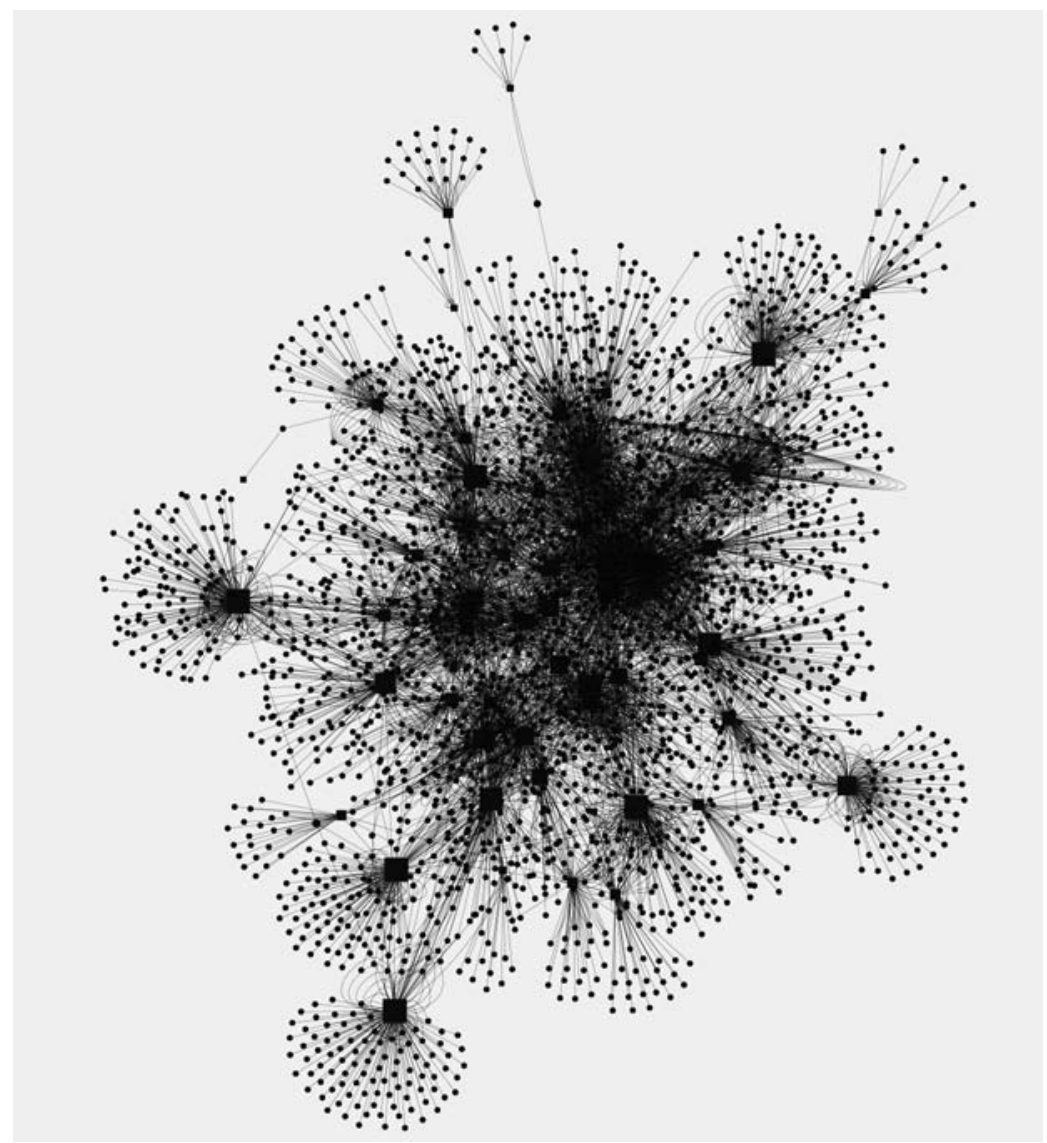

Figure 1. Underlying Collaboration Networks of X Network Members

The second step was to calculate each member's betweenness centrality (BC) in the network. $\mathrm{BC}$ is computed as the proportion of all shortest paths in a network that pass through a given node (Carrington, Scott, \& Wasserman, 2005; Scott, 2000; Wasserman \& Faust, 1994). As such, although it belongs to the many measures of network centrality (Borgatti, 2005; Freeman, 1978/79; Wasserman \& Faust, 1994), BC is quite independent from the notion of being close to the theoretical "centre" of a network; instead, it has more to do with the notion of being an important, and thus central, bridge in a network. Also, since BC is computed as a proportion of total potential paths in a network, it has a theoretical range of $0-1$, but average nodes $\mathrm{BC}$ in a network will decrease as networks grow.

In the sociograms, each node represents a researcher and each collaboration tie is drawn as a line between two researchers. We used the Prefuse force directed layout algorithm to optimize visual representation. This algorithm belongs to a particular approach called "force-directed" (Cline et al., 2007; Shannon et al., 


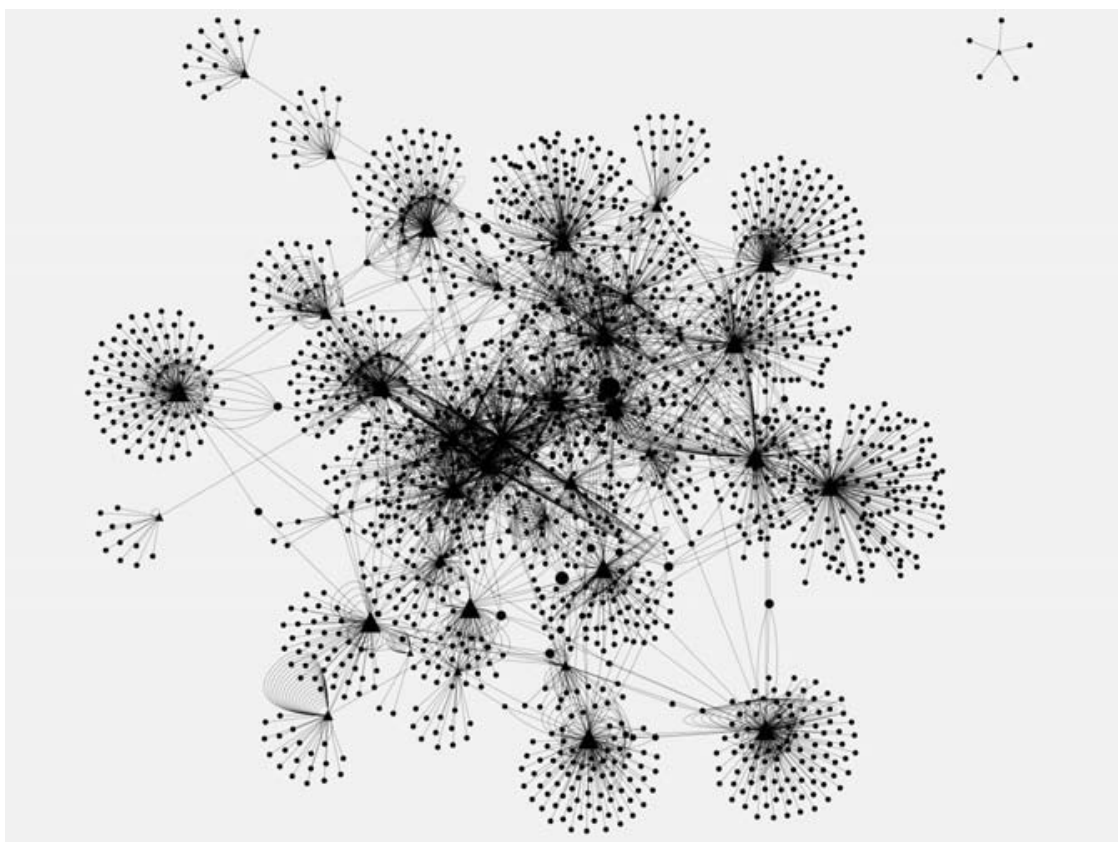

Figure 2. Underlying Collaboration Networks of Y Network Members

2003). Force-directed sociograms are optimized from the principle that nodes are mutually repulsive to each other, while ties constitute attractive forces. The optimization aims to balance those forces so that interconnected nodes are closer to each other. We also plotted sociograms 1 and 2 such that node size corresponds to betweenness centrality scores (lowest BC score as smaller dots and higher scores as larger dots). The node shape relates to the researcher's formal membership in each network (squares for members of the $\mathrm{X}$ network, triangles for the Y network, circles for non-members). In Figure 3, researchers affiliated to only one of the networks are indicated in light grey (again with squares for members of the $\mathrm{X}$ network, triangles for the $\mathrm{Y}$ network), while those whose name appears in both networks are shown as a dark grey circle; the three formal members of both networks are shown as black arrow shapes.

\section{Measuring academic performance}

In this study, the X network and Y network researchers' performance was measured with an influence-focused bibliometric indicator called the $h$-index. Unlike other indicators that measure only researchers' number of publications, the $h$-index evaluates a scholar's cumulative impact by combining the number of publications and their citation impact (see Hirsch, 2005, on the calculation of the $h$-index). Being one of the first indicators to combine both the volume and impact of individual publications, it has become an easy and recognized tool to evaluate 


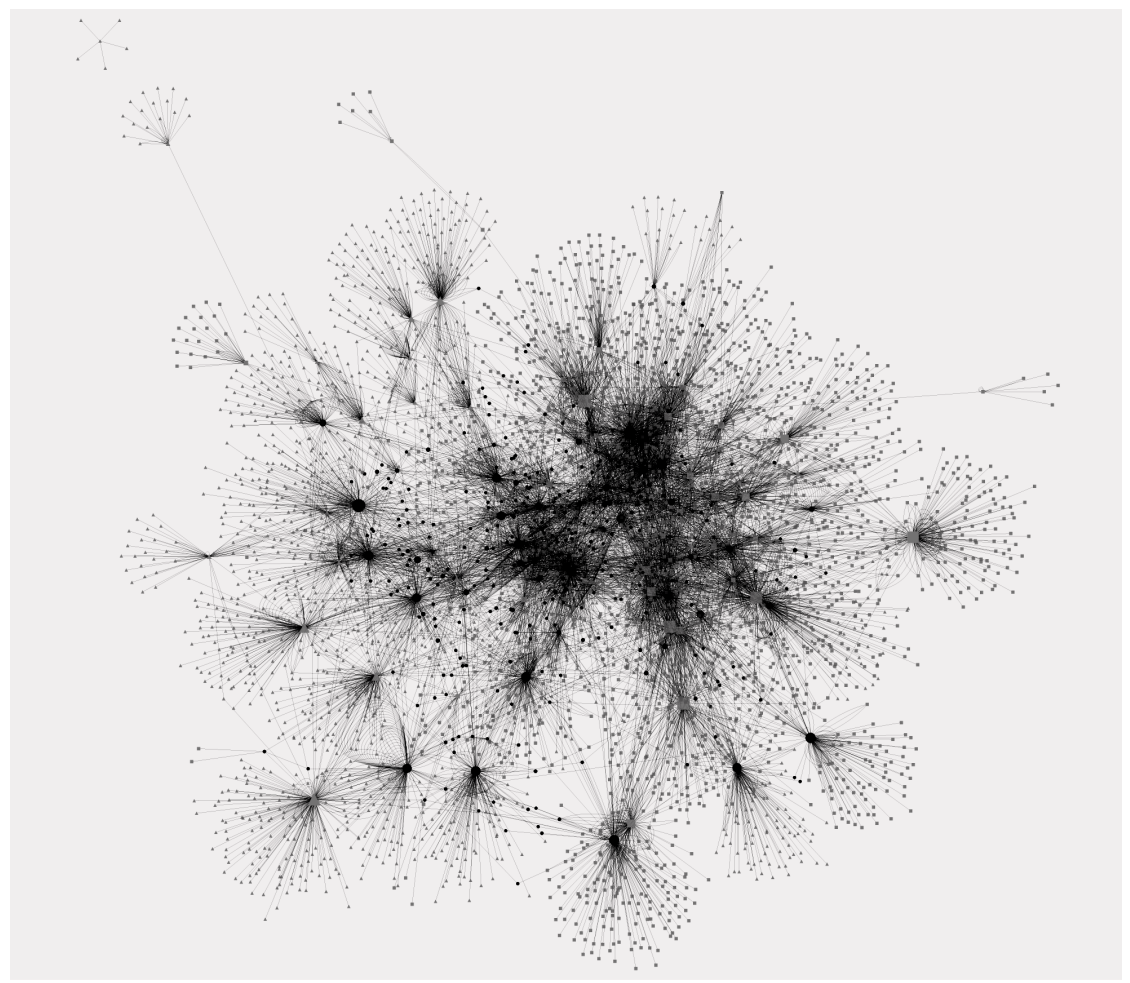

\section{Figure 3. $X$ and $Y$ Merged Network}

scientific performance (Abbasi et al., 2014; Bornmann \& Daniel, 2009). Despite its growing popularity and quality, the $h$-index does not, of course, entirely solve the inherent complexity of measuring performance.

We retrieved the $h$-indexes of all X network and Y network members through Harzing's Publish or Perish, a free software program that calculates the score based on a scholar's available publications in Google Scholar (Harzing, 2010). Other databases also offer the possibility of calculating the $h$-index, and scores can vary from one database to another (e.g. Scopus, Web of Science). Studies have shown that, overall, none of these databases stands out as consistently more reliable than the others, and each has different strengths and weaknesses (De Groote \& Raszewski, 2012; Vieira \& Gomes, 2009). The $h$-index calculation largely favours scholars with longer careers, since they generally have more publications (Bornmann $\&$ Daniel, 2009). To reduce this bias, we calculated the $h$-index of each researcher over a five-year period only (2010-2014).

\section{Structural position and performance correlations}

To measure the association between structural position and performance, we computed correlation scores between structural position (betweenness centrality) 
and academic performance ( $h$-index) measures. We believe that BC is the most relevant structural measure to assess this association, for two reasons. The first is derived from graph theory, which posits that network connectivity depends primarily on shortest paths. This implies that if researcher A is on the shortest path between researchers $\mathrm{B}$ and $\mathrm{C}$, then $\mathrm{A}$ will have a more important role in information transmission between $\mathrm{B}$ and $\mathrm{C}$ than will researcher $\mathrm{D}$, who also connects $\mathrm{B}$ and $\mathrm{C}$, but through a longer path. The second reason is anchored in sociological applications of Granovetter's (1983) and Burt's (1992) theories on the strengths of weak ties and structural holes, which we explained in the previous section.

To measure the correlations between BC and $h$-index, we standardized our measures and first used Pearson's $r$ coefficient. However, as this coefficient is sensitive to extreme values, we also used Spearman's rho. Simple linear regression coefficients with $95 \%$ CIs were calculated to measure the strength of the association between the centrality and performance variables. These analyses were then repeated after eliminating individuals with extreme values (mean +3 standard deviations). The correlation analyses were performed with SPSS 22 software.

\section{RESULTS}

Our study leads to two main findings. First, the organic collaborative network underlying $\mathrm{X}$ and $\mathrm{Y}$ networks shows that collaboration ties span larger than the two formal networks and overlap significantly between both networks. Second, results indicate that the performance of X network and Y network members is correlated with their structural position (betweenness centrality) in the underlying organic collaborative network. Before discussing these two findings further, we present some of the features of the two networks and their underlying collaborative structure that emerge from our findings.

The two networks created with the data extracted from the CVs of X network and Y network members present similar structural features. Both have a dense core of interconnections and a periphery composed of network members working mostly with external collaborators (see Figures 1 and 2). In both cases, there is no obvious visible relation between researchers' structural metrics and the distance of their node from the centre or the periphery of the network. The absence of relation between measured centrality and the position on the graph is an artifact of our sampling strategy. Given our sampling approach, the sociograms are centred on the two institutional networks under study. However, the measured node centrality includes collaborations with both members and non-members and, as such, is related to the underlying organic "real" network of collaboration.

Furthermore, in Figure 3 it is visually striking to see the level of interconnectedness of the two networks, given that they formally have only three members in common. When analyzed separately (Figures 1 and 2), the X network underlying collaboration network forms a single interconnected component, whereas the Y network is composed of one interconnected main component and a small isolated component (located at the top right corner of the graph, Figure 2). The isolate consists of a single 
Y network member who has no direct connection with any other Y network member and whose external collaborators $(n=5)$ also are not connected to any of the other researchers who are part of the main component. Since BC cannot be compared with disconnected components, this isolated member was removed from the sampling, leaving a total of 125 members in the analysis.

The X network underlying collaboration network includes 2,788 researchers ( $83 \mathrm{X}$ network formal members and 2,705 external collaborators), with 7,816 collaboration ties among them. The main component of the underlying Y network collaboration network includes 1,836 researchers ( 45 formal Y network members and 1,791 external collaborators), with 4,393 collaboration ties among them.

The number of collaborations per X network member researcher (degree of the node) ranged from 1 to 452 , for an average of 110 collaborations established with an average of 57 different persons (minimum 1, maximum 168). The number of intra-X network collaborations (collaborations between X network member researchers) ranged from 0 to 120 , for an average of 32 collaborations with an average of 13 different members (minimum 0 , maximum 40). X network members' $h$-index varied between 0 and 21, with an average of 5 .

In the Y network underlying collaboration network, the number of collaborations per member researcher ranged from 5 to 385, for an average of 112 collaborations established with an average of 53 different persons (minimum 1, maximum 168). The number of intra-Y network collaborations ranged from 0 to 150 , for an average of 27 collaborations with an average of 5 different members (minimum 0 , maximum 19). Y network members' $h$-index varied between 0 and 19 , with an average of 6.89 .

When the two networks are merged, the number of researchers forming the network drops from 4,624 to 4,258, indicating an $8.6 \%$ overlap in $\mathrm{X}$ and $\mathrm{Y}$ networks' underlying collaborative structures. In the merged network, three researchers out of $125(2.4 \%)$ are regular members of both X network and Y network. However, 50 other researchers out of $125(40 \%)$ are regular X network members with ties in the Y network or regular Y network members with ties in the $\mathrm{X}$ network. Table 1 shows the distribution of $\mathrm{X}$ network members, $\mathrm{Y}$ network members, and external collaborators in the merged network. In Figure 3, researchers who have connections in both networks $(n=366)$ are represented by dark grey circles clustered in the centre, while researchers who are connected only within the $\mathrm{X}$ network (square nodes) and researchers who are connected only within the Y network (triangle nodes) make up the periphery. In the merged network, the average number of collaborations for each of the 125 members in the main component is 111.68 , and the $h$-index average is 5.69 .

Regarding the association between structural position and research performance, our data show that all variables (degree, $h$-index, and BC) are positively correlated in the three networks. Table 2 provides basic information on structural position (centrality) and academic performance variables, while Table 3 provides the correlation scores and regression coefficients between $\mathrm{BC}$ and $h$-index. 
Table 1. Distribution of $X$ Network Members, $Y$ Network Members, and External Collaborators in the X-Y Merged Network

\begin{tabular}{lllllr}
\hline $\begin{array}{l}\text { Network } \\
\text { affiliation }\end{array}$ & $\begin{array}{l}\text { Formal } \\
\text { network } \\
\text { members }\end{array}$ & $\begin{array}{l}\text { X network for- } \\
\text { mal members } \\
\text { who appear } \\
\text { in data from } Y \\
\text { network }\end{array}$ & $\begin{array}{l}\text { Y network for- } \\
\text { mal members } \\
\text { who appear } \\
\text { in data from X } \\
\text { network }\end{array}$ & $\begin{array}{l}\text { Non-members } \\
\text { appearing in } \\
\text { the data }\end{array}$ & Total \\
\hline $\begin{array}{l}\text { Both X net- } \\
\text { work and }\end{array}$ & 3 & 27 & 20 & 316 & 366 \\
$\begin{array}{l}\text { Y network } \\
\text { OnlyY } \\
\text { network }\end{array}$ & 22 & N/A & N/A & 1,448 & 1,476 \\
$\begin{array}{l}\text { Only X } \\
\text { network }\end{array}$ & 53 & N/A & N/A & 2,369 & 2,422 \\
\begin{tabular}{l} 
Total \\
\hline
\end{tabular} & 78 & 27 & 20 & 4,133 & 4,258 \\
\hline
\end{tabular}

Table 2. Descriptive Analysis of Centrality and Performance Variable for the Three Networks

\begin{tabular}{lllll}
\hline & & $\begin{array}{l}\text { Betweenness } \\
\text { centrality } \\
(\mathbf{2 0 1 4 )}\end{array}$ & $\begin{array}{l}\text { Degree (Number } \\
\text { of collaborations) } \\
(\mathbf{2 0 1 4 )}\end{array}$ & $\begin{array}{l}\boldsymbol{h} \text {-index } \\
(\mathbf{2 0 1 0}-\mathbf{2 0 1 4})\end{array}$ \\
\hline X network & $M$ & 0.032 & 109.53 & 5 \\
collaborative & $S D$ & 0.028 & 87.717 & 3.774 \\
network $(n=83)$ & Minimum & 0 & 1 & 0 \\
& Maximum & 0.106 & 452 & 21 \\
Y network & $M$ & 0.054 & 111.822 & 6.889 \\
collaborative & $S D$ & 0.050 & 86.226 & 4.524 \\
network ( $n=45)$ & Minimum & 0 & 5 & 0 \\
& Maximum & 0.174 & 385 & 19 \\
X-Y merged & $M$ & 0.021 & 111.68 & 5.688 \\
network (main & $S D$ & 0.019 & 86.641 & 4.174 \\
component: & Minimum & 0 & 1 & 0 \\
$n=125$ ) & Maximum & 0.07 & 452 & 21 \\
\hline
\end{tabular}

The most conceptually important correlation in this study is the one between $h$-index and BC. The strong association between these two metrics supports our hypothesis that researchers' structural position is associated with performance measures. In the three networks (X network, Y network, and merged network), highly statistically significant correlation scores demonstrate that the $h$-index is associated with BC. 
Table 3. Correlation and Simple Linear Regression Coefficients Between Betweenness Centrality and $h$-Index

\begin{tabular}{|c|c|c|c|}
\hline & $\begin{array}{l}\text { Betweenness } \\
\text { centrality (2014) }\end{array}$ & & $\begin{array}{l}h \text {-index } \\
\text { (normalized) } \\
(2010-2014) \\
\end{array}$ \\
\hline \multirow{6}{*}{$\begin{array}{l}\text { X network } \\
\text { collaborative } \\
\text { network }\end{array}$} & \multirow{3}{*}{$\begin{array}{l}N=83 \text { (entire } \\
\text { sample) }\end{array}$} & Pearson's correlation & $0.458^{*}$ \\
\hline & & Spearman's rho & $0.460^{*}$ \\
\hline & & $\begin{array}{l}\text { Linear regression coefficient } \\
(\mathrm{Cl} 95 \%)\end{array}$ & $\begin{array}{l}16.496(9.413 ; \\
23.579)\end{array}$ \\
\hline & \multirow{3}{*}{$\begin{array}{l}n=81 \text { (sample after } \\
\text { removal of two indi- } \\
\text { viduals with extreme } \\
\text { productivity values) }\end{array}$} & Pearson's correlation & $0.435^{*}$ \\
\hline & & Spearman's Rho & $0.464^{*}$ \\
\hline & & $\begin{array}{l}\text { Linear regression coefficient } \\
\text { (Cl 95\%) }\end{array}$ & $\begin{array}{l}14.654(7.869 ; \\
21.438)\end{array}$ \\
\hline \multirow{6}{*}{$\begin{array}{l}\text { Y network } \\
\text { collaborative } \\
\text { network }\end{array}$} & \multirow{3}{*}{$\begin{array}{l}N=45 \text { (main } \\
\text { component) }\end{array}$} & Pearson's correlation & $.631^{*}$ \\
\hline & & Spearman's rho & $.713^{*}$ \\
\hline & & $\begin{array}{l}\text { Linear regression coefficient } \\
(\mathrm{Cl} 95 \%)\end{array}$ & $\begin{array}{l}12.526(7.785 ; \\
17.267)\end{array}$ \\
\hline & \multirow{3}{*}{$\begin{array}{l}n=44 \text { (sample after } \\
\text { removal of one indi- } \\
\text { vidual with extreme } \\
\text { productivity values) }\end{array}$} & Pearson's correlation & $0.652^{*}$ \\
\hline & & Spearman's rho & $0.724^{*}$ \\
\hline & & $\begin{array}{l}\text { Linear regression coefficient } \\
\text { (CI 95\%) }\end{array}$ & $\begin{array}{l}13.621(8.687 ; \\
18.554)\end{array}$ \\
\hline \multirow{6}{*}{$\begin{array}{l}X-Y \text { merged } \\
\text { network }\end{array}$} & \multirow{3}{*}{$\begin{array}{l}N=125 \text { (main com- } \\
\text { ponent) }\end{array}$} & Pearson's correlation & $0.547^{*}$ \\
\hline & & Spearman's Rho & $0.555^{*}$ \\
\hline & & $\begin{array}{l}\text { Linear regression coefficient } \\
\text { (CI 95\%) }\end{array}$ & $\begin{array}{l}29.319 \\
(21.310 \\
37.328)\end{array}$ \\
\hline & \multirow{3}{*}{$\begin{array}{l}n=122 \text { (sample } \\
\text { after removal of } \\
\text { three individuals } \\
\text { with extreme pro- } \\
\text { ductivity values) }\end{array}$} & Pearson's correlation & $0.513^{*}$ \\
\hline & & Spearman's rho & $0.551^{*}$ \\
\hline & & $\begin{array}{l}\text { Linear regression coefficient } \\
(\mathrm{Cl} 95 \%)\end{array}$ & $\begin{array}{l}26.351 \\
(18.382 ; \\
34.321)\end{array}$ \\
\hline
\end{tabular}

${ }^{*} p<0.001$

\section{DISCUSSION}

Probably relying on the face-value idea that collaboration breeds productivity, funding agencies worldwide are increasingly promoting the creation of formal networks and funding collaboration-based initiatives in the hope that those investments will enhance research capacity. Although many studies have shown that collaboration indeed enhances research productivity, it is much less clear whether funding delivered through programs intended specifically to promote collaboration is achieving its objective. One objective of this study was to examine the association between formal institutional research networks, researchers' actual 
collaborative patterns, and their academic performance. Our findings demonstrate that actual collaborations do increase research productivity but that these collaborations are not necessarily linked to formal institutional networks. Visual analysis of $\mathrm{X}$ and $\mathrm{Y}$ networks suggests that formal networks have very little relation to the underlying organic network of their researchers' collaborations. This, in turn, suggests that funding formal research networks may not have a significant effect on actual collaborative practices. As both networks provide resources (e.g. information, money, support) to their members, it is plausible that they have an impact (of unknown magnitude) on their members' productivity. However, the face-value idea that funding thematic collaboration networks will drive more thematic collaboration and that this will, in turn, boost productivity is not obvious from the results obtained here. In our view, this has significant implications both for the internal management of these formal networks and for the agencies that provide funding (in this context, Quebec's FRQ-S).

Regarding more specifically the level of overlap between the two institutional networks we analyzed, our study shows that even though they are relatively independent networks (only three members out of 125 are official members of both networks), members' collaborative dynamics show a significant overlap. Although the total overlap (both members and collaborators) is $8 \%$ (366 researchers appear in both networks), the percentage of regular X network or Y network members who have connections in both networks is $40 \%$. This difference is probably partly explained by our sampling strategy; since our database does not include external collaborators' own collaboration activities, it is impossible to know whether some of them are linked with other external collaborators in the sample. If these collaboration ties were known, the total overlap would likely be higher. Again, this finding suggests that institutional structures do not fit squarely with the actual underlying collaboration network uniting researchers. The significant number of external collaborations shows that institutional networks are only one source of collaboration among many others. What is difficult to assess, however, is whether these collaborative patterns predated the creation of institutional networks or were formed without regard to individuals' participation in the institutional research networks. Longitudinal analysis of the changes in collaborative patterns would complement our findings and help assess whether the institutional structure ultimately has any effect on collaboration dynamics.

The second important finding of our study is the positive association between researchers' structural position in collaborative networks and their scientific performance (measured by the $h$-index). One plausible explanation for this covariation could be that researchers occupying a bridging position in a network are more likely to have a higher performance than those connected with mostly the same small group of researchers in all their activities. This explanation of the statistical association is consistent with a few other similar studies (Abbasi, Chung, \& Hossain, 2012; Abbasi, et al., 2014; Ebadi \& Schiffauerova, 2015a). As briefly discussed earlier, there are convincing sociological foundations for the idea that structural position influences social and market 
success (Burt, 1992; Granovetter, 1983). Collaborative relations are part of a researcher's social capital, as they provide commodities, such as research ideas and financial resources, or opportunities to join other research projects and to exchange knowledge with experienced peers (Sonnenwald, 2007). In turn, those commodities potentially translate into researchers' actual scientific performance. This tallies with the idea that researchers in a bridging position will have greater access to such commodities than those who maintain redundant ties with a closed cluster of individuals.

Visual analysis of Figure 3 shows that some researchers positioned at the periphery of the graph and with very limited ties to X network or Y network cores display very high $\mathrm{BC}$ scores. This indicates that some of the most bridging and highest-performing researchers are not necessarily at the core of either of the two formal institutional networks and rely more on external collaborations. This could be explained by the fact that both networks are relatively recent. As mentioned earlier, other studies focusing on more mature networks did find that the institutional network had a structuring effect on collaboration patterns and, incidentally, on scientific performance (Ponomariov \& Boardman, 2010). Another possible explanation for our results could be related to the organizational characteristics of the networks under study. The X network and Y network networks do not represent a major funding source for members, and participation in the activities of the network is on a voluntary basis; research networks that have stronger participation incentives might have a different effect from what our findings indicate.

Even if our findings suggest that collaborations established within the institutional network are not a determining factor in individual research performance, these results do not imply that research centres or networks have no value. First, as other studies have shown, it is possible that the situation will change over the longer term. As mentioned earlier, assessing this would require a longitudinal analysis of X and Y networks. Second, in terms of policy, the importance of formal networking structures depends mostly on the criteria chosen to define network "success" (Corley, et al., 2006). Beyond enhancing research performance, a network can be considered successful for many other equally important reasons (e.g. members' desire to participate in such collective structures, the intangible benefits of collaborations, or the emergence of new research topics and modes of doing research that would not have come out in other contexts).

Nevertheless, in our view the results suggest that there might be a need for a better alignment of organizational structures with underlying "organic" structures. In this sense, we support Corley et al's (2006, p. 990) statement that "research collaboration effectiveness is beneficially viewed in terms of the optimal fit of the degree and type of institutionalization and the epistemic character of the research fields." By "the epistemic character of research fields", the authors are referring to the often implicit rules and norms that bring certain groups of researchers together, and these are central elements to explain the formation of the underlying "organic" collaborative networks that we describe in this article. 


\section{LIMITATIONS AND CONCLUSIONS}

Some limitations might affect this study's results. First, regarding data collection sources, the use of CVs alone provides access to specific explicit forms of collaboration, such as the production of a collective article or grant proposal. It does not take into account all forms of informal collaborations that might also have an influence on a researcher's performance (e.g. sharing ideas with colleagues, exchanging and commenting on future scientific contributions, engaging in relationships of mentorship or mutual support).

Second, as mentioned earlier, it is not possible to map out a network structure that is effectively limitless, and the social network method chosen focuses only on a portion of the larger scientific network. Correlation results might present some variations if the network sample was larger.

Finally, this study does not focus on the personal and social factors that influence researchers' ability to build "productive" collaborations. Factors such as seniority and reputation (Pezzoni, et al., 2012), gender and ethnicity, motives for collaboration (Lee \& Bozeman, 2005), personal affinity, geographical location and capacity to build international collaborations (Barjak \& Robinson, 2008; Lakitan, et al., 2012; Leydesdorff \& Wagner, 2008), and access to funding resources (Defazio et al., 2009; Ebadi \& Schiffauerova, 2015a, 2015b) all influence a researcher's capacity to establish collaborations as well as the impact that his or her scientific contributions will have.

Despite the limitations and unresolved questions discussed above, we believe our study provides important practical insights. As more and more funding is funnelled into formal "collaboration-focused" initiatives that aim to span disciplines, roles, and institutions, it becomes crucial both to discuss the conceptual soundness of those investments and to develop evaluation tools to assess their effectiveness. This paper provides insights at three levels. First, it defends the idea that the evaluation of research networks ought to distinguish between organic and formal-funded and managed-collaboration networks. Second, while our data exhibit very significant covariation between researchers' structural position and productivity, the results also show that there is little overlap between formal networks' membership and the organic collaboration structures. Finally, if collaboration indeed matters, it remains to be seen whether collaboration processes and patterns can (and even should) be deliberately managed through targeted funding. If funding bodies and universities are to continue investing in programs aiming to stimulate research collaboration, they will need more sophisticated evaluation tools to measure the impact of those investments. The SNA-based method of network mapping presented here is, in our view, a powerful tool for this purpose. It can help in assessing the convergence between formal networks and actual collaborations and to measure the association between structural position and productivity. With current computer standardization of CV data, the methodology that we used in this study becomes easily scalable. 


\section{REFERENCES}

Abbasi, A., Chung, K.S.K., \& Hossain, L. (2012). Egocentric analysis of co-authorship network structure, position and performance. Information Processing \& Management, 48(4), 671-679. https://doi.org/10.1016/j.ipm.2011.09.001

Abbasi, A., Wigand, R.T., \& Hossain, L. (2014). Measuring social capital through network analysis and its influence on individual performance. Library \& Information Science Research, 36(1), 66-73. https://doi.org/10.1016/j.lisr.2013.08.001

Abramo, G., D’Angelo, C.A., \& Di Costa, F. (2009). Research collaboration and productivity: Is there correlation? Higher Education, 57(2), 155-171. https://doi.org/10.1007/ s10734-008-9139-Z

Barjak, F., \& Robinson, S. (2008). International collaboration, mobility and team diversity in the life sciences: Impact on research performance. Social Geography, 3(1), 23-36. https://doi.org/10.5194/sg-3-23-2008

Borgatti, S.P. (2005). Centrality and network flow. Social Networks, 27(1), 55-71. https:// doi.org/10.1016/j.socnet.2004.11.008

Borgatti, S.P., \& Halgin, D.S. (2011). On network theory. Organization Science, 22(5), 1168-1181. https://doi.org/10.1287/orsc.1100.0641

Bornmann, L., \& Daniel, H.-D. (2009). The state of $h$ index research. Is the $h$ index the ideal way to measure research performance? EMBO Reports, 10(1), 2-6. https://doi. org/10.1038/embor.2008.233

Bourdieu, P. (1980). Le sens pratique. Paris, France: Éditions de Minuit.

Bourdieu, P. (1984). Espace social et genèse des «classes». Actes de la recherche en sciences sociales, 52/53, 3-14. https://doi.org/10.3406/arss.1984.3327

Bourdieu, P., \& Passeron, J.-P. (1970). La reproduction: Éléments pour une théorie du système d'enseignement. Paris, France: Les éditions de Minuit.

Burt, R.S. (1992). Structural holes: The social structure of competition. Cambridge, MA: Harvard University Press.

Carrington, P.J., Scott, J., \& Wasserman, S. (Eds.). (2005). Models and methods in social network analysis. New York, NY: Cambridge University Press. https://doi.org/10.1017/ CBO9780511811395

Canadian Institutes of Health Research (CIHR). (2015). Health research roadmap II: Capturing innovation to produce better health and health care for Canadians. Strategic plan 2014-15-2018-19. Ottawa, ON: Canadian Institutes of Health Research.

Cline, M.S., Smoot, M., Cerami, E., Kuchinsky, A., Landys, N., Workman, C., . . . \& B Bader, G.D. (2007). Integration of biological networks and gene expression data using Cytoscape. Nature Protocols, 2(10), 2366-2382. https://doi.org/10.1038/nprot.2007.324

Contandriopoulos, D., Duhoux, A., Larouche, C., \& Perroux, M. (2016). The impact of a researcher's structural position on scientific performance: An empirical analysis. PLoS One, 11(8), e0161281. https://doi.org/10.1371/journal.pone.0161281

Corley, E.A., Boardman, P.C., \& Bozeman, B. (2006). Design and the management of multiinstitutional research collaborations: Theoretical implications from two case studies. Research Policy, 35(7), 975-993. https://doi.org/10.1016/j.respol.2006.05.003 
Crane, D. (1972). Invisible colleges: Diffusion of knowledge in scientific communities. Chicago, IL: University of Chicago Press.

De Groote, S.L., \& Raszewski, R. (2012). Coverage of Google Scholar, Scopus, and Web of Science: A case study of the h-index in nursing. Nursing Outlook, 60(6), 391-400. https://doi.org/10.1016/j.outlook.2012.04.007

Defazio, D., Lockett, A., \& Wright, M. (2009). Funding incentives, collaborative dynamics and scientific productivity: Evidence from the EU framework program. Research Policy, 38(2), 293-305. https://doi.org/10.1016/j.respol.2008.11.008

Dundar, H., \& Lewis, D.R. (1998). Determinants of research productivity in higher education. Research in Higher Education, 39(6), 607-631. https://doi.org/10.1023/A:1018705823763

Duque, R.B., Ynalvez, M., Sooryamoorthy, R., Mbatia, P., Dzorgbo, D.-B.S., \& Shrum, W. (2005). Collaboration paradox: Scientific productivity, the Internet, and problems of research in developing areas. Social Studies of Science, 35(5), 755-785. https://doi. org/10.1177/0306312705053048

Ebadi, A., \& Schiffauerova, A. (2015a). How to become an important player in scientific collaboration networks? Journal of Informetrics, 9(4), 809-825. https://doi.org/10.1016/j. joi.2015.08.002

Ebadi, A., \& Schiffauerova, A. (2015b). How to receive more funding for your research? Get connected to the right people! PLoS One, 10(7), e0133061. https://doi.org/10.1371/ journal.pone.0133061

Freeman, L.C. (1978/79). Centrality in social networks conceptual clarification. Social Networks, 1(3), 215-239. https://doi.org/10.1016/0378-8733(78)90021-7

Fonds de recherche du Québec (FRQ-S). (2015). Plan stratégique 2014-2017. Quebec, QC: Gouvernement du Québec.

Granovetter, M. (1983). The strength of weak ties: A network theory revisited. Sociological Theory, 1, 201-233. https://doi.org/10.2307/202051

Granovetter, M. (1985). Economic action and social structure: The problem of embeddedness. American Journal of Sociology, 91(3), 481-510. https://doi.org/10.1086/228311

Hagstrom, W.O. (1965). The scientific community. New York, NY: Basic Books.

Harzing, A.-W. (2010). The publish or perish book: Your guide to effective and responsible citation analysis. Melbourne, Australia: Tarma Software Research.

Hirsch, J.E. (2005). An index to quantify an individual's scientific research output. Proceedings of the National Academy of Sciences of the United States of America, 102(46), 16569-16572. https://doi.org/10.1073/pnas.0507655102

Hoekman, J., Frenken, K., \& Tijssen, R.J.W. (2010). Research collaboration at a distance: Changing spatial patterns of scientific collaboration within Europe. Research Policy, 39(5), 662-673. https://doi.org/10.1016/j.respol.2010.01.012

Katz, J.S., \& Martin, B.R. (1997). What is research collaboration? Research Policy, 26(1), 1-18. https://doi.org/10.1016/S0048-7333(96)00917-1

Kilduff, M., \& Brass, D.J. (2010). Organizational social network research: Core ideas and key debates. Academy of Management Annals, 4(1), 317-357.

Knoke, D., \& Yang, S. (2008). Social network analysis. Thousand Oaks, CA: SAGE Publications. https://doi.org/10.4135/9781412985864. 
Kyvik, S. (2013). The academic researcher role: Enhancing expectations and improved performance. Higher Education, 65(4), 525-538. https://doi.org/10.1007/s10734-0129561-0

Lakitan, B., Hidayat, D., \& Herlinda, S. (2012). Scientific productivity and the collaboration intensity of Indonesian universities and public R\&D institutions: Are there dependencies on collaborative R\&D with foreign institutions? Technology in Society, 34(3), 227-238. https://doi.org/10.1016/j.techsoc.2012.06.001

Lamont, M., \& Molnár, V. (2002). The study of boundaries in the social sciences. Annual Review of Sociology, 28(1), 167-195. https://doi.org/10.1146/annurev. soc.28.110601.141107

Landry, R., Traore, N., \& Godin, B. (1996). An econometric analysis of the effect of collaboration on academic research productivity. Higher Education, 32(3), 283-301. https:// doi.org/10.1007/BF00138868

Lee, S., \& Bozeman, B. (2005). The impact of research collaboration on scientific productivity. Social Studies of Science, 35(5), 673-702. https://doi.org/10.1177/0306312705052359

Lewis, J.M. (2006). Being around and knowing the players: Networks of influence in health policy. Social Science \& Medicine, 62(9), 2125-2136. https://doi.org/10.1016/j. socscimed.2005.10.004

Leydesdorff, L., \& Wagner, C.S. (2008). International collaboration in science and the formation of a core group. Journal of Informetrics, 2(4), 317-325. https://doi. org/10.1016/j.joi.2008.07.003

Martín-Sempere, M., Garzón-García, B., \& Rey-Rocha, J. (2008). Team consolidation, social integration and scientists' research performance: An empirical study in the biology and biomedicine field. Scientometrics, 76(3), 457-482. https://doi.org/10.1007/ s11192-007-1866-x

Milard, B. (2014). The social circles behind scientific references: Relationships between citing and cited authors in chemistry publications. Journal of the Association for Information Science and Technology, 65(12), 2459-2468. https://doi.org/10.1002/asi.23149

Moody, J. (2004). The structure of a social science collaboration network: Disciplinary cohesion from 1963 to 1999. American Sociological Review, 69(2), 213-238. https:// doi.org/10.1177/000312240406900204

Newman, M.E.J. (2004). Coauthorship networks and patterns of scientific collaboration. Proceedings of the National Academy of Sciences of the United States of America, 101(Suppl 1), 5200-5205. https://doi.org/10.1073/pnas.0307545100

Pezzoni, M., Sterzi, V., \& Lissoni, F. (2012). Career progress in centralized academic systems: Social capital and institutions in France and Italy. Research Policy, 41(4), 704-719. https://doi.org/10.1016/j.respol.2011.12.009

Ponomariov, B.L., \& Boardman, P.C. (2010). Influencing scientists' collaboration and productivity patterns through new institutions: University research centers and scientific and technical human capital. Research Policy, 39(5), 613-624. https://doi. org/10.1016/j.respol.2010.02.013

Porac, J.F., Wade, J.B., Fischer, H.M., Brown, J., Kanfer, A., \& Bowker, G. (2004). Human capital heterogeneity, collaborative relationships, and publication patterns in a 
multidisciplinary scientific alliance: A comparative case study of two scientific teams. Research Policy, 33(4), 661-678. https://doi.org/10.1016/j.respol.2004.01.007

Prell, C. (2012). Social network analysis: History, theory and methodology. London \& Thousand Oaks, CA: SAGE Publications.

Putnam, R.D. (2000). Bowling alone: America's declining social capital. In L. Crothers \& C. Lockhart (Eds.), Culture and politics: A reader (pp. 223-234). New York, NY: Palgrave Macmillan.

Scott, J. (2000). Social network analysis: A handbook (2nd ed.). Thousand Oaks, CA: SAGE Publications.

Scott, J., \& Carrington, P.J. (2011). The SAGE handbook of social network analysis. London: SAGE Publications.

Shannon, P., Markiel, A., Ozier, O., Baliga, N.S., Wang, J.T., Ramage, D., . . \& \& Ideker, T. (2003). Cytoscape: A software environment for integrated models of biomolecular interaction networks. Genome Research, 13(11), 2498-2504. https://doi.org/10.1101/ gr.1239303

Sonnenwald, D.H. (2007). Scientific collaboration. Annual Review of Information Science \& Technology, 41(1), 643-681. https://doi.org/10.1002/aris.2007.1440410121

Tuire, P., \& Erno, L. (2001). Exploring invisible scientific communities: Studying networking relations within an educational research community. A Finnish case. Higher Education, 42(4), 493-513. https://doi.org/10.1023/A:1012242009758

Vieira, E.S., \& Gomes, J.A.N.F. (2009). A comparison of Scopus and Web of Science for a typical university. Scientometrics, 81(2), 587-600. https://doi.org/10.1007/s11192009-2178-0

Wasserman, S., \& Faust, K. (1994). Social network analysis: Methods and applications. Cambridge, England: Cambridge University Press. https://doi.org/10.1017/ CBO9780511815478

Ynalvez, M.A., \& Shrum, W.M. (2011). Professional networks, scientific collaboration, and publication productivity in resource-constrained research institutions in a developing country. Research Policy, 40(2), 204-216. https://doi.org/10.1016/j.respol.2010.10.004

\section{AUTHOR INFORMATION}

Damien Contandriopoulos is a professor in the Faculty of Nursing at l'Université de Montréal.

Catherine Larouche is a postdoctoral fellow at the Max Planck Institute for Social Anthropology.

Arnaud Duhoux is an assistant professor in the Faculty of Nursing at l'Université de Montréal. 